\title{
O ESTADO DE COISAS INCONSTITUCIONAL FACE AO REITERADO ROMPIMENTO DE BARRAGENS NO BRASIL
}

\section{EL ESTADO DE COSAS INCONSTITUCIONAL FRENTE AL REITERADO ROMPIMIENTO DE REPRESAS EN BRASIL}

Henrique Rosmaninho Alves ${ }^{1}$

\begin{abstract}
RESUMO
O presente estudo tem como objetivo averiguar a possibilidade de caracterização do Estado de Coisas Inconstitucional face ao quadro de reiterado rompimento de barragens no país. Para tanto analisou-se o histórico de desastres com barragens ocorridos ao longo dos últimos anos, os danos provocados por estes eventos, a legislação em vigor sobre segurança de barragens e o conteúdo e requisitos essenciais do Estado de Coisas Inconstitucional. Realizou-se uma investigação jurídicosociológica, visto que se partiu da análise do fenômeno socioambiental, relativamente à sua origem e abrangência, para posteriormente debruçar-se sobre a legislação vigente e o cabimento da tese do Estado de Coisas Inconstitucional, momento no qual o estudo adquiriu um viés jurídico-dogmático. Trata-se de uma pesquisa qualitativa, predominantemente bibliográfica, na qual adotou-se como marco teórico a concepção de Estado de Coisas Inconstitucional emanada pela Corte Constitucional da Colômbia, empregando-se o raciocínio dedutivo para a resolução do problema proposto. Concluise pelo cabimento da caracterização do Estado de Coisas Inconstitucional ao cenário de reiterados rompimentos de barragens, propondo-se a adoção de cinco medidas para auxiliar na promoção da superação do $\mathrm{ECI}$ no caso em tela.
\end{abstract}

Palavras-chave: Rompimento de Barragens; Estado de Coisas Inconstitucional; Desastres.

\section{ABSTRACT}

The present study has as objective to investigate the possibility of characterization of the State of Things Unconstitutional in the face of the repeated rupture of dams in the country. For that, we analyzed the history of disasters with dams that have occurred in recent years, the damage caused by these events, the current legislation on dam safety and the essential content and requirements of the State of Things Unconstitutional. A juridical-sociological investigation was carried out, since it was based on the analysis of

${ }^{1}$ Doutorando em Direito Constitucional na PUC/MINAS. Mestre em Direito Ambiental pela Escola Superior Dom Helder Câmara. Graduado em Direito pela PUC/MINAS. Professor no IMEC/BETIM e na FISBE. Advogado. E- mail : henrique_rosmaninhoalves@outlook.com ORCID ID https://orcid.org/00000002-5980-2046 
the socioenvironmental phenomenon, with respect to its origin and scope, to later examine the current legislation and the fitting of the thesis of the State of Things Unconstitutional, at which time the study has acquired a legal-dogmatic bias. It is a qualitative research, predominantly bibliographical, in which the conception of the State of Things Unconstitutional emanated by the Constitutional Court of Colombia was adopted as a theoretical framework, using the deductive reasoning to solve the proposed problem. The conclusion of the characterization of the Unconstitutional State of Things to the scenario of repeated dam breaks is proposed, proposing the adoption of five measures to assist in promoting the overcoming of the $\mathrm{ECl}$ in the case in hand.

Key-words: Dam Disruption; State of Things Unconstitutional; Disasters.

\section{INTRODUÇÃO}

O rompimento reiterado de barragens no Brasil ao longo dos últimos anos acarretou elevados danos à população atingida pelo desastre, afetando diretamente diversos de seus direitos fundamentais, como o direito à vida, à saúde, à moradia, à propriedade e ao meio ambiente ecologicamente equilibrado.

Diante disso buscou-se analisar o histórico de rompimento de barragens ocorridos nos últimos anos, atentando-se aos danos provocados em cada um destes eventos, bem como a legislação pertinente a segurança de barragens fazendo-se uma análise mais detida sobre a Política Nacional de Segurança de Barragem.

Face à percepção do cenário de manutenção de rompimento reiterado de barragens e do número de barragens classificadas como de alto risco mesmo após a criação de um aparato legal destinado especificamente para promover a segurança de barragens passou-se ao exame da possibilidade de caracterização do Estado de Coisas Inconstitucional relativamente ao quadro de violação massiva de direitos fundamentais decorrente do reiterado rompimento de barragens no país.

Neste ponto encontra-se o problema proposto pelo presente estudo, qual seja: é cabível a caracterização do estado de coisas inconstitucional face ao quadro de reincidência de rompimentos de barragens no Brasil?

Aponta-se como hipótese que face ao reiterado rompimento de barragens no Brasil, bem como a manutenção do aspecto quantitativo dos danos decorrentes do impacto de tais fenômenos é possível a declaração do estado de coisas 
inconstitucional, porque tal cenário cumpre todos os seus pressupostos de caracterização.

Foram propostos três objetivos específicos a serem alcançados pela investigação, quais sejam: constatar as barragens em que houve rompimento nas últimas duas décadas; identificar a legislação existente referente à segurança de barragens no Brasil e identificar os dados quantitativos dos danos decorrentes dos rompimentos das barragens de Mariana e Brumadinho, tendo-se como objetivo geral do presente estudo averiguar se é possível a caracterização do Estado de Coisas Inconstitucional face ao quadro de reiterado rompimento de barragens no país.

Trata-se de uma investigação jurídico-sociológica, visto que se partiu da análise do fenômeno socioambiental, relativamente à sua origem e abrangência, para posteriormente debruçar-se sobre a legislação vigente e o cabimento da tese do Estado de Coisas Inconstitucional, momento na qual o estudo adquiriu um viés jurídicodogmático. De caráter qualitativo e com uso de pesquisa predominantemente bibliográfica, o estudo adota como marco teórico a concepção de Estado de Coisas Inconstitucional emanada pela Corte Constitucional da Colômbia, empregando-se o raciocínio dedutivo para a resolução do problema proposto.

Desde o ano de 2001 ocorreram no Brasil 11 desastres decorrentes do rompimento de barragens, dentre os quais 6 foram em Minas Gerais. Nesses eventos, mais de 100 óbitos foram confirmados, mais de 250 pessoas ficaram desaparecidas, aproximadamente 7.000 pessoas restaram desalojadas ou desabrigadas, incalculáveis prejuízos materiais e danos ambientais imensuráveis foram provocados. No estado de Minas Gerais, local da maioria dos desastres citados, existem mais de 700 barragens, fazendo-se necessário o presente estudo, no intuito de tentar colaborar com a produção de conhecimento no país acerca do tema e superar o estado de permanente insegurança que se encontra a população localizada na área de influência de barragens.

Pretende-se através das medidas propostas pelo presente estudo, colaborar com a promoção de maior segurança à população e consequentemente com a ampliação da proteção dos direitos fundamentais à vida, saúde, moradia, propriedade e ao meio ambiente ecologicamente equilibrado. 


\section{HISTÓRICO DE ROMPIMENTO DE BARRAGENS NO BRASIL}

O rompimento de barragens sejam elas de rejeitos ou de outra espécie não são eventos recentes, mas sim, trata-se de uma modalidade de desastre reiterada na história da humanidade.

Inclusive naquele que provavelmente é o maior desastre da história da humanidade, a "enchente do rio Huan He (rio amarelo) em 1887"2, ocorreu a ruptura dos diques do rio.

Séculos de construções e reparações dos diques haviam empurrado o curso principal do rio cada vez mais para o alto, depositando-o a 23 metros das terras ao seu redor. Depois de um longo verão de chuvas torrenciais contínuas, milhões de fazendeiros encolheram-se em seus campos encharcados, esperando pelo inevitável. $E$ ele veio com um rugido. Quando o Huan He transbordou, rompeu os diques, varrendo mais de trezentas vilas, onze grandes cidades e milhões de pessoas. A água da enchente criou instantaneamente um lago do tamanho do Ontário, avançando ainda mais de 50 mil milhas quadradas e destruindo tudo que encontrava pelo caminho. Um vento forte completou a devastação. Durante vários dias, foi impossível dar início aos trabalhos de resgate e reconstrução - e a essa altura doenças como tifo e disenteria já castigavam os sobreviventes. Uma onda de fome foi inevitável. Foi a enchente mais letal da História. (BROWN; et al, 2012, p.19)

O evento supracitado ficou conhecido como "Tristeza da China", havendo estimativas que apontam ter sido responsável pela morte de mais de mais de 3 (três) milhões de pessoas. Apenas para se ter uma noção, tal contingente de pessoas equivale a população ${ }^{3}$ dos municípios de Betim/MG (432.575), Contagem/MG (659.070) e Belo Horizonte/MG (2.501.576), os quais possuem juntos 3.593.221 habitantes.

\footnotetext{
2 "O rio Huang He transbordou 1593 vezes registradas em quatro milênios, com efeitos catastróficos". Uma curiosidade é que ele já foi utilizado como uma defesa natural. "Em 1938, Chiang Kai-shek, líder do Kuomintang e do Governo Nacional, ordenou que os diques do rio fossem abertos para impedir a invasão dos japoneses. A enchente cessou rapidamente o avanço das tropas, mas o que se seguiu foi um impasse militar. A ordem de Chiang de inundar a planície acabou tendo consequências desastrosas, matando mais de meio milhão de fazendeiros chineses.

${ }^{3}$ Estimativa de população realizada pelo IBGE para o ano de 2018. Disponível em: <ftp://ftp.ibge.gov.br/Estimativas de Populacao/Estimativas 2018/estimativa TCU 2018 20190107.pdf>
} 
Cerca de 900 mil morreram no primeiro fluxo e estima-se que mais de 1,3 milhão se afogaram. Outra estimativa é que de 3 (três) a 4 (quatro) milhões morreram de doenças causadas pela água da enchente, com um tapete de lama de 2,5 m de profundidade. (BROWN; et al, 2012, p.19)

Embora com dimensões incomparavelmente menores, em diversas outras ocasiões o rompimento o de barragens foi a causa de desastres pelo planeta. É o que se demonstra na Tabela 1 adiante:

Tabela 1 - Rompimentos de Barragem no Planeta

\begin{tabular}{|c|c|c|c|c|c|}
\hline LOCAL & DATA & $\begin{array}{l}\text { NOME DA } \\
\text { BARRAGEM }\end{array}$ & $\begin{array}{l}\text { TIPO DE } \\
\text { BARRAGEM }\end{array}$ & $\begin{array}{l}\text { DANOS } \\
\text { CAUSADOS }\end{array}$ & CAUSA PRIMÁRIA \\
\hline $\begin{array}{l}\text { Los } \\
\text { Angeles } \\
\text { (EUA) }\end{array}$ & $\begin{array}{l}12 / 03 / 192 \\
8\end{array}$ & St. Francis & $\begin{array}{l}\text { Barragem de água } \\
\text { para } \\
\text { abastecimento. }\end{array}$ & 450 óbitos & $\begin{array}{l}\text { Colapso das fundações da } \\
\text { barragem e deslizamentos de terra } \\
\text { provocados pela pressão do } \\
\text { volume de água para a qual foi } \\
\text { planejada. (falhas exclusivamente } \\
\text { tecnológicas) }\end{array}$ \\
\hline $\begin{array}{l}\text { Riviera } \\
\text { Francesa } \\
\text { (FRA) }\end{array}$ & 2/12/1959 & Malpasset & $\begin{array}{l}\text { Barragem de água } \\
\text { para } \\
\text { abastecimento. }\end{array}$ & $\begin{array}{l}\text { Mais de } 420 \\
\text { óbitos. }\end{array}$ & $\begin{array}{l}\text { Pressão excepcional de água } \\
\text { proveniente de chuvas torrenciais, } \\
\text { composição da rocha da margem } \\
\text { esquerda e falha geológica a uma } \\
\text { curta distância do rio abaixo. } \\
\text { (falhas tecnológicas somadas a } \\
\text { eventos naturais extremos). }\end{array}$ \\
\hline $\begin{array}{l}\text { Dolomitas } \\
\text { (ITA) }\end{array}$ & 9/10/1963 & Vajont & $\begin{array}{l}\text { Barragem de água } \\
\text { para geração de } \\
\text { energia. }\end{array}$ & $\begin{array}{l}\text { Entre } 2000 \text { e } \\
2600 \text { óbitos. }\end{array}$ & $\begin{array}{l}\text { A barragem não se rompeu mais } \\
\text { houve um vazamento de água } \\
\text { gigantesco provocado por um } \\
\text { deslizamento de } 260 \text { milhões de } \mathrm{m}^{3} \\
\text { de terra e rochas que atingiu as } \\
\text { água da barragem, causando uma } \\
\text { onde de } 250 \text { metros que varreu o } \\
\text { vale abaixo. (falhas tecnológicas } \\
\text { somadas a eventos naturais } \\
\text { extremos). }\end{array}$ \\
\hline $\begin{array}{l}\text { Idaho } \\
\text { (EUA) }\end{array}$ & $5 / 6 / 1976$ & Teton & $\begin{array}{l}\text { Barragem de água } \\
\text { para diversos } \\
\text { propósitos, } \\
\text { inclusive proteção } \\
\text { contra enchentes. }\end{array}$ & 11 óbitos & $\begin{array}{l}\text { Infiltração e crateras na } \\
\text { extremidade direita da barragem, } \\
\text { causadas por erros de engenharia. } \\
\text { Como o desastre foi previsto com } \\
\text { horas de antecedência as cidades } \\
\text { situadas abaixo, Wilford e Rexburg, } \\
\text { foram evacuadas, o que reduziu } \\
\text { consideravelmente o número de } \\
\text { mortes. (falhas exclusivamente }\end{array}$ \\
\hline
\end{tabular}




\begin{tabular}{|c|c|c|c|c|c|}
\hline & & & & & tecnológicas) \\
\hline $\begin{array}{l}\text { Marinduque } \\
\text { (FIL) }\end{array}$ & $24 / 3 / 1996$ & Mogpog & $\begin{array}{l}\text { Barragem de } \\
\text { rejeitos de minério. }\end{array}$ & $\begin{array}{l}\text { Não houve } \\
\text { mortes diretas, } \\
\text { mas pouco tempo } \\
\text { depois pessoas } \\
\text { apresentaram } \\
\text { doenças } \\
\text { relacionadas ao } \\
\text { lixo tóxico, dentre } \\
\text { as quais várias } \\
\text { vieram a óbito. } 0 \\
\text { Rio Boac foi } \\
\text { contaminado e } \\
\text { considerado sem } \\
\text { vida, centenas de } \\
\text { pessoas ficaram } \\
\text { desabrigadas. }\end{array}$ & (Sem informações). \\
\hline $\begin{array}{l}\text { Província } \\
\text { de Henan } \\
(\mathrm{CHN})\end{array}$ & $8 / 8 / 1975$ & Banqiao & $\begin{array}{l}\text { Barragem de água } \\
\text { para controlar } \\
\text { enchentes e gerar } \\
\text { eletricidade. }\end{array}$ & $\begin{array}{l}25 \text { mil óbitos pela } \\
\text { enchente e } 135 \\
\text { por } \\
\text { consequências } \\
\text { posteriores. }\end{array}$ & $\begin{array}{l}\text { O tufão Nina gerou uma } \\
\text { tempestade de período de retorno } \\
\text { de } 2 \text { mil anos e foi responsáve } \\
\text { pelo colapso da barragem de } \\
\text { Banqiao, Shimantan e um } \\
\text { complexo de } 62 \text { barragens } \\
\text { menores. (causas naturais } \\
\text { tecnológicas) OBS: Conforme } \\
\text { Brown, o hidrólogo Chen Xing } \\
\text { havia alertado para a necessidade } \\
\text { da introdução de } 12 \text { portas eclusas } \\
\text { na barragem, mas apenas } 5 \text { foram } \\
\text { adotadas. }\end{array}$ \\
\hline $\begin{array}{l}\text { Quebec } \\
\text { (CAN) }\end{array}$ & 19/7/1996 & Há!Há! & Barragem de água. & $\begin{array}{l}\text { Entre } 7 \text { e } 10 \\
\text { óbitos. } 16 \text { mil } \\
\text { pessoas foram } \\
\text { evacuadas, } 488 \\
\text { casas destruídas. }\end{array}$ & $\begin{array}{l}\text { Chuvas torrenciais entre } 18 \text { e } 21 \text { de } \\
\text { julho elevaram o nível das águas } \\
\text { do lago "Há!Há!", mesmo com a } \\
\text { liberação do excedente de água o } \\
\text { dique leste do lago rompeu e os } \\
\text { escombros foram arrastados } \\
\text { atingido uma vila inteira. (causas } \\
\text { naturais e estruturais) }\end{array}$ \\
\hline $\begin{array}{l}\text { New } \\
\text { Orleans } \\
(\text { EUA) }\end{array}$ & $\begin{array}{l}\mathrm{De} \\
23 / 0 / 2005 \\
\mathrm{a} \\
30 / 8 / 2005\end{array}$ & $\begin{array}{l}\text { Sistema } \\
\text { federal de } \\
\text { diques. }\end{array}$ & Barragem de água & $\begin{array}{l}1836 \text { óbitos e } 705 \\
\text { desaparecidos } \\
\text { em decorrência } \\
\text { do furacão } \\
\text { Katrina, } \\
\text { especificamente } \\
\text { em função do } \\
\text { rompimento dos } \\
\text { diques não há } \\
\text { informações. }\end{array}$ & $\begin{array}{l}\text { A passagem do furacão Katrina, o } \\
\text { sexto mais forte já registrado, } \\
\text { causou o rompimento do sistema } \\
\text { federal de diques em New Orleans, } \\
\text { o que resultou na inundação de } \\
80 \% \text { da cidade. Alertas precoces } \\
\text { sobre o furacão resultaram na } \\
\text { evacuação de milhares de } \\
\text { pessoas, a reduzindo } \\
\text { consideravelmente o número de } \\
\text { mortes, no entanto, muitos }\end{array}$ \\
\hline
\end{tabular}




\begin{tabular}{|c|c|c|c|c|c|}
\hline & & & & & $\begin{array}{l}\text { moradores não conseguiram deixar } \\
\text { o local o vieram a óbito. (causas } \\
\text { naturais e estruturais) }\end{array}$ \\
\hline $\begin{array}{l}\text { Virgínia } \\
\text { (EUA) }\end{array}$ & $\begin{array}{l}26 / 02 / 197 \\
2\end{array}$ & $\begin{array}{l}\text { Barragem } 3 \\
\text { da } \\
\text { Companhia } \\
\text { Pittson Coal. }\end{array}$ & $\begin{array}{l}\text { Barragem de } \\
\text { resíduos líquidos. }\end{array}$ & $\begin{array}{l}125 \text { mortos, } 1.121 \\
\text { feridos, } \\
\text { aproximadamente } \\
4.000 \\
\text { desabrigados. }\end{array}$ & $\begin{array}{l}\text { No dia } 22 \text { de fevereiro a barragem } \\
3 \text { havia sido inspecionada e } \\
\text { considerada "satisfatória", no } \\
\text { entanto, quatro dias depois, com o } \\
\text { advento de fortes chuvas a } \\
\text { barragem se rompeu, lançando } 500 \\
\text { milhões de resíduos líquidos de } \\
\text { carvão sobre os habitantes de } \\
\text { Buffalo Creek Hollow. (falhas } \\
\text { tecnológicas e fenômenos } \\
\text { naturais). }\end{array}$ \\
\hline $\begin{array}{l}\text { Andaluzia } \\
\text { (ESP) }\end{array}$ & $\begin{array}{l}25 / 09 / 199 \\
8\end{array}$ & $\begin{array}{l}\text { Barragem da } \\
\text { Boliden. }\end{array}$ & $\begin{array}{l}\text { Barragem de } \\
\text { resíduos de zinco, } \\
\text { ferro e cádmio. }\end{array}$ & $\begin{array}{l}\text { Danos ambientais } \\
\text { de longo prazo. } \\
\text { Mortadade de } \\
\text { peixes e poluição } \\
\text { do rio Guadiamar. }\end{array}$ & $\begin{array}{l}\text { Falhas estruturais foram } \\
\text { constatadas anos antes por um } \\
\text { relatório encomendado pela } \\
\text { Boliden, no entanto providencias } \\
\text { não foram tomadas e a barragem } \\
\text { veio a colapso. Brown assevera } \\
\text { que provavelmente a causa da } \\
\text { negligencia foi uma relação de } \\
\text { custo benefício, já que as multas } \\
\text { por poluição ambiental na Espanha } \\
\text { eram irrisórias. (BROWN; et al, } \\
2012 \text { ) }\end{array}$ \\
\hline
\end{tabular}

Fonte: (elaboração própria, 2019)

O Brasil não escapa dessa realidade, tendo em sua história recente dois desastres por rupturas de barragens de elevadas proporções, responsáveis por danos ambientais imensuráveis, pela morte de centenas de pessoas além de danos materiais incomensuráveis, quais sejam, o rompimento das Barragens do Fundão na cidade de Mariana e da Barragem da Mina do Córrego do Feijão em Brumadinho, ambas cidades localizadas no Estado de Minas Gerais.

Mencionado estado, que traz no nome uma de suas importantes características naturais e sua principal vocação econômica, é o estado da federação que mais possui barragens de rejeitos, o que decorre da grande exploração mineral realizada em seu território.

Apenas na região conhecida como "quadrilátero ferrífero" há atualmente centenas de barragens. É nesta região que situa-se a cidade de Mariana, mas o rompimento da barragem do Fundão não foi o primeiro no local. 
A Tabela 2 contém todos os desastres decorrentes de rompimento de barragens ocorridos no Brasil nos últimos 35 anos:

Tabela 2 - Rompimentos de Barragem no Brasil

\begin{tabular}{|c|c|c|c|c|}
\hline LOCAL & ANO & NOME & TIPO & DANOS CAUSADOS \\
\hline Itabirito (MG) & 1986 & $\begin{array}{ll}\text { Barragem de } \\
\text { Fernandinho }\end{array}$ & $\begin{array}{l}\text { Barragem de } \\
\text { rejeitos } \\
\text { minerários. }\end{array}$ & 7 óbitos \\
\hline Nova Lima (MG) & 2001 & $\begin{array}{ll}\text { Barragem } & \text { de } \\
\text { Macacos } & \end{array}$ & $\begin{array}{l}\text { Barragem de } \\
\text { rejeitos } \\
\text { minerários. }\end{array}$ & 5 óbitos \\
\hline Cataguases (MG) & 2003 & $\begin{array}{ll}\text { Barragem } & \text { em } \\
\text { Cataguases } & \end{array}$ & $\begin{array}{l}\text { Barragem de } \\
\text { rejeitos } \\
\text { industriais. }\end{array}$ & $\begin{array}{l}\text { Contaminação do rio Paraíba } \\
\text { do Sul, mortandade de animais } \\
\text { e peixes e interrupção do } \\
\text { abastecimento de água de } \\
600.000 \text { pessoas. }\end{array}$ \\
\hline Alagoa Nova (PB) & 2004 & Camará & $\begin{array}{l}\text { Barragem de } \\
\text { água. }\end{array}$ & $\begin{array}{l}5 \text { óbitos e aproximadamente } 3 \\
\text { mil pessoas desabrigadas ou } \\
\text { desalojadas. }\end{array}$ \\
\hline Miraí (MG) & 2007 & $\begin{array}{l}\text { Barragem da Rio } \\
\text { Pomba/Cataguases }\end{array}$ & $\begin{array}{l}\text { Barragem de } \\
\text { rejeitos } \\
\text { minerários. }\end{array}$ & $\begin{array}{l}\text { Mais de } 4000 \text { pessoas } \\
\text { desabrigadas ou desalojadas. }\end{array}$ \\
\hline Vilhena (RO) & 2008 & Apertadinho & $\begin{array}{lr}\text { Barragem } & \text { de } \\
\text { água } & \text { para } \\
\text { geração } & \text { de } \\
\text { energia. } & \end{array}$ & $\begin{array}{l}\text { Danos ambientais variados } \\
\text { (assoreamento de rios, erosão } \\
\text { do solo, entre outros). }\end{array}$ \\
\hline $\begin{array}{l}\text { Cocal e Buriti dos Lopes } \\
\text { (PI) }\end{array}$ & 2009 & Algodões & $\begin{array}{l}\text { Barragem de } \\
\text { água. }\end{array}$ & $\begin{array}{lrrr}\text { Entre } \quad 9 \quad \text { e } & 24 & \text { mortos } & \text { e } \\
\text { aproximadamente } & 2000 \\
\text { pessoas ficaram desabrigadas } \\
\text { ou desalojadas. }\end{array}$ \\
\hline Laranjal do Jari (AP) & 2014 & Santo Antônio & $\begin{array}{lr}\text { Barragem } & \text { de } \\
\text { água } & \text { para } \\
\text { geração } & \text { de } \\
\text { energia. } & \end{array}$ & 4 óbitos. \\
\hline Itabirito (MG) & 2014 & $\begin{array}{l}\text { Barragem } \\
\text { Herculano. }\end{array}$ & $\begin{array}{l}\text { Barragem de } \\
\text { rejeitos } \\
\text { minerários. }\end{array}$ & 3 óbitos. \\
\hline Mariana (MG) & 2015 & Barragem Fundão & $\begin{array}{l}\text { Barragem de } \\
\text { rejeitos } \\
\text { minerários. }\end{array}$ & $\begin{array}{l}19 \text { óbitos, } 8 \text { desaparecidos } 600 \\
\text { desabrigados ou desalojados, } \\
\text { interrupção do abastecimento } \\
\text { de água de milhares de } \\
\text { pessoas e poluição do rio São }\end{array}$ \\
\hline
\end{tabular}




\begin{tabular}{|c|c|c|c|c|}
\hline & & & & $\begin{array}{l}\text { Francisco e do mar no ES, } \\
\text { interrupção da atividade } \\
\text { pesqueira e afetação ao } \\
\text { Turismo em Regência/ES. }\end{array}$ \\
\hline Mariana (MG) & 2015 & Barragem Santarém & $\begin{array}{l}\text { Barragem de } \\
\text { rejeitos } \\
\text { minerários. }\end{array}$ & $\begin{array}{l}19 \text { óbitos, } 8 \text { desaparecidos } 600 \\
\text { desabrigados ou desalojados, } \\
\text { interrupção do abastecimento } \\
\text { de água de milhares de } \\
\text { pessoas e poluição do rio São } \\
\text { Francisco e do mar no ES, } \\
\text { interrupção da atividade } \\
\text { pesqueira e afetação ao } \\
\text { Turismo em Regência/ES. }\end{array}$ \\
\hline $\begin{array}{l}\text { São José do Rio Claro } \\
\text { (MT) }\end{array}$ & 2018 & $\begin{array}{l}5 \text { Barragens de uma } \\
\text { pequena } \\
\text { hidrelétrica. }\end{array}$ & $\begin{array}{l}\text { Barragem de } \\
\text { água. }\end{array}$ & $\begin{array}{l}\text { Nenhum óbito, queda de uma } \\
\text { ponte e destruição da } \\
\text { vegetação marginal de um } \\
\text { trecho do rio Arinos. }\end{array}$ \\
\hline Brumadinho (MG) & 2019 & $\begin{array}{l}\text { Barragem da Minas } \\
\text { do Córrego do } \\
\text { Feijão. }\end{array}$ & $\begin{array}{l}\text { Barragem de } \\
\text { rejeitos } \\
\text { minerários. }\end{array}$ & $\begin{array}{l}84 \text { óbitos, } 276 \text { desaparecidos, } \\
\text { centenas de desalojados, } \\
\text { afetação do Turismo pela } \\
\text { interdição do museu Inhotim. } \\
\text { Dados atualizados até } 29 \text { de } \\
\text { janeiro de } 2019 \text {. }\end{array}$ \\
\hline
\end{tabular}

Fonte: (elaboração própria, 2019)

O rompimento de barragens pode ser classificado como um desastre misto ou tecnológico, a depender do fato que motivou a ruptura. Quando a causa primária for o impacto causado por um fenômeno natural intenso, responsável por abalar a estrutura da barragem o desastre será misto, no entanto, quando for o mau planejamento ou um erro na execução das obras de construção ou manutenção que cause o colapso da estrutura, tratar-se-á de um desastre tecnológico.

Em função da reincidência de desastres com barragens no Brasil, foi elaborada na última década uma vasta legislação sobre o tema, bem como realizados diversos estudos pelos institutos de pesquisa governamentais e por universidades, os quais foram responsáveis por identificar o atual cenário das barragens de rejeitos espalhadas pelo país.

Abordar-se-á adiante os dados quantitativos das barragens atualmente existentes no país, bem como as diferenciações entre os diversos tipos de barragens e a legislação atinente a tais estruturas. 


\subsection{Legislação brasileira aplicável as barragens}

A Lei Federal oㅜ12.334/2010 responsável por estabelecer a Política Nacional de Segurança de Barragens - PNSB, em seu art. $2^{\circ}$, inciso I, define barragem como "qualquer estrutura em um curso permanente ou temporário de água para fins de contenção ou acumulação de substâncias líquidas ou de misturas de líquidos e sólidos, compreendendo o barramento e as estruturas associadas". (BRASIL, 2010)

O Departamento de Aguas e Energia Elétrica do estado de São Paulo - DAAE conceitua barragens em sua Portaria ํo 717 de 1996 como:

Todo maciço cujo eixo principal esteja num plano que intercepte um curso d'água e respectivos terrenos marginais, alterando as suas condições de escoamento natural, formando reservatório de água a montante, o qual tem finalidade única ou múltipla. (DAEE/SP, 1996)

A Associação Brasileira de Normas Técnicas, no bojo da NBR 13028 define barragens como sendo "qualquer estrutura que forma uma parede de contenção para rejeitos, para sedimentos e/ou para formação do reservatório de água". (ABNT, 2017)

Percebe-se pela leitura dos conceitos supracitados que as barragens apresentam uma variedade de finalidades, sendo as mais corriqueiras o depósito de rejeitos oriundos da exploração mineral, a geração de energia elétrica, abastecimento de água para o consumo humano, a irrigação de áreas de plantio e a dessedentação de animais.

As barragens são classificadas geralmente como convencionais (de terra, gravidade, arco, enrocamento, concreto e mista) ou não-convencionais (gabião, madeira, alvenaria de pedra, entre outras).

Conforme Alexander Marques Silva acredita-se que 43,7\% das grandes barragens do planeta são convencionais de terra. $O$ autor sustenta que embora no Brasil inexistam dados confiáveis acerca da quantidade de barragens de terra e mista (terra-enrocamento), "é de notório saber, tratarem-se das maiores quantidades numéricas, por se tratarem de agregados mais econômicos". (SILVA, 2017, p.79)

Independentemente do tipo de barragem, como estas estruturas utilizam grande volume de recursos hídricos e alteram cursos d'água e as bacias hidrográficas das 
regiões onde se situam, compete a União realizar a gestão destas e definir critérios de outorga de direitos para sua utilização.

É o que dispõe o artigo 21, inciso XIX da CR/1988:

Art. 21. Compete à União:

XIX - instituir sistema nacional de gerenciamento de recursos hídricos e definir critérios de outorga de direitos de seu uso; (BRASIL, 1988)

Cabe destacar que como as barragens destinam-se corriqueiramente a geração de energia elétrica e ao depósito de rejeitos minerários, a ingerência da União nestas fundamenta-se também nos incisos VIII e IX do artigo 20 da CR/1988, os quais determinam serem seus bens "os potenciais de energia hidráulica" e "os recursos minerais, inclusive os do subsolo". (BRASIL, 1988)

O artigo 176 da CR/1988, no mesmo sentido, reitera que "as jazidas, em lavra ou não, e demais recursos minerais e os potenciais de energia hidráulica constituem propriedade distinta da do solo, para efeito de exploração ou aproveitamento, e pertencem à União", determinando que compete a União a emissão de autorização ou concessão para a pesquisa e a lavra de recursos minerais, bem como para 0 aproveitamento dos potenciais de energia hidráulica.

Referidas determinações constitucionais acarretaram na elaboração de diversas leis aplicáveis a barragens, dentre as quais a de maior relevância é a Lei no 12.334/2010, embora deve-se destacar também a Lei no 9.433/1997 e a Lei no 9.984/2000.

A Lei no 9.433/1997 responsável por instituir a Política Nacional de Recursos Hídricos aponta como competência do Conselho Nacional de Recursos Hídricos:

(...) zelar pela implementação da Política Nacional de Segurança de Barragens (PNSB); estabelecer diretrizes para implementação da PNSB, aplicação de seus instrumentos e atuação do Sistema Nacional de Informações sobre Segurança de Barragens (SNISB) e; apreciar o Relatório de Segurança de Barragens, fazendo, se necessário, recomendações para melhoria da segurança das obras, bem como encaminhá-lo ao Congresso Nacional (Art.35, XI, XII e XIII). (BRASIL, 1997)

Por sua vez, a Lei no 9.984/2000 responsável por criar a Agência Nacional de Águas, inclui no rol de suas competências organizar, implantar e gerir o Sistema 
Nacional de Informações sobre Segurança de Barragens (SNISB); promover a articulação entre os órgãos fiscalizadores de barragens, e; coordenar a elaboração do Relatório de Segurança de Barragens e encaminhá-lo, anualmente, ao Conselho Nacional de Recursos Hídricos (CNRH), de forma consolidada, conforme determinação de seu artigo 4ㄴ, incisos XX, XXI e XXII.

O diploma legal de maior relevância sobre o tema, a Lei o 12.334/2010, popularmente conhecida como Política Nacional de Segurança de Barragens trata-se do marco regulatório da segurança de barragens no Brasil. Referida lei é aplicável a qualquer tipo de barragem, não se atendo a determinados tipos.

\subsection{Política Nacional de Segurança de Barragens}

A Política Nacional de Segurança de Barragens, instituída pela Lei $\mathrm{n}^{-}$ 12.334/2010 tem como objetivos "garantir a observância de padrões de segurança de barragens de maneira a reduzir a possibilidade de acidente e suas consequências; regulamentar as ações de segurança a serem adotadas nas fases de planejamento, projeto, construção, primeiro enchimento e primeiro vertimento, operação, desativação e de usos futuros de barragens em todo o território nacional; promover o monitoramento e o acompanhamento das ações de segurança empregadas pelos responsáveis por barragens; criar condições para que se amplie o universo de controle de barragens pelo poder público, com base na fiscalização, orientação e correção das ações de segurança; coligir informações que subsidiem o gerenciamento da segurança de barragens pelos governos; estabelecer conformidades de natureza técnica que permitam a avaliação da adequação aos parâmetros estabelecidos pelo poder público e; fomentar a cultura de segurança de barragens e gestão de riscos". (BRASIL, 2010)

Para propiciar o cumprimento de seus objetivos a PNSB dispõe de alguns instrumentos, os quais estão elencados no artigo 6ํ da Lei no 12.334/2010:

Art. $6^{\circ}$ São instrumentos da Política Nacional de Segurança de Barragens (PNSB):

I - o sistema de classificação de barragens por categoria de risco e por dano potencial associado; 
II - o Plano de Segurança de Barragem;

III - o Sistema Nacional de Informações sobre Segurança de Barragens (SNISB);

IV - o Sistema Nacional de Informações sobre o Meio Ambiente (Sinima);

V - o Cadastro Técnico Federal de Atividades e Instrumentos de Defesa Ambiental;

VI - o Cadastro Técnico Federal de Atividades Potencialmente Poluidoras ou Utilizadoras de Recursos Ambientais;

VII - o Relatório de Segurança de Barragens. (BRASIL, 2010)

Além dos instrumentos previstos no artigo $6^{0}$ destaca-se também o Plano de Ação Emergencial, instrumento previsto no artigo 11 da referida legislação, que terá sua elaboração determinada pelo órgão fiscalizador em função da categoria de risco e do dano potencial associado à barragem, sendo exigido sempre nas hipóteses em que a barragem for classificada como de dano potencial associado alto.

O Plano de Ação Emergencial deverá prever as ações que serão executadas pelo empreendedor da barragem em situações de emergência, assim como apontará os agentes que deverão ser notificados do evento.

Dentre diversos aspetos o PAE deverá abordar a identificação e análise das possíveis situações de emergência; os procedimentos para identificação e notificação de mau funcionamento ou de condições potenciais de ruptura da barragem; estabelecer procedimentos preventivos e corretivos a serem adotados em situações de emergência, com indicação do responsável pela ação; e criar uma estratégia e meio de divulgação e alerta para as comunidades potencialmente afetadas em situação de emergência.

Interessante mencionar que o PAE deve ficar disponível no empreendimento e nas prefeituras envolvidas, bem como ser encaminhado às autoridades competentes e aos organismos de defesa civil.

Alexander Marques Silva, ao abordar o PAE especificamente das Barragens de Minério, assevera:

O Plano de Ação de Emergência de Barragens de Minério - PAEBM é um documento técnico, a ser elaborado pelo empreendedor, no qual estão identificadas as situações de emergência que possam pôr em risco a integridade da barragem e estabelecidas as ações mitigadoras ou solucionadoras e definidos os agentes a serem notificados de tais ocorrências, com o objetivo de reduzir a possibilidade de danos materiais às propriedades e às comunidades a jusante e as perdas de vidas humanas ou não. Outro fator diferenciador do Plano de Ação de Emergência das Barragens de Minério - PAEBM, em relação ao PAE de 
outros tipos de barragens está diretamente relacionado com o dano potencial associado ${ }^{4}$, haja vista que 0 distanciamento das áreas de ajuda ou socorro são maiores nas contenções de minério a forma de elaboração será também diferida. Isso se deve por alguns motivos, como exemplo, a barragem de rejeito, em regra, encontra-se em área inóspita, privada, com a população a jusante ou a montante e não às margens como em barragens hidrelétricas ou de lazer, devido ao fato dos tipos de danos ocasionados serem de proporão elevada em termos comparativos e das providências a serem adotadas divergirem... (SILVA, 2017 , p. 140,141$)$

De fato o PAEBM trata-se de um instrumento com grande potencial para reduzir danos em casos de desastres, caso seja de conhecimento efetivo da população. Isto porque ao conhecer os prováveis danos ocasionados no caso de concretização do evento adverso, bem como os prováveis locais em que os mesmos incidirão, a população poderá tomar medidas preventivas emergenciais no intuito de ao menos mitigar os danos humanos.

Veja-se que o Departamento Nacional de Pesquisa Mineral, através da Portaria nํ 526, de 9 de dezembro de 2013, precisamente em seu artigo 2ํㅜㄹ inciso XI define como "zona de autossalvamento" a região a jusante da barragem para a qual se considera não haver tempo suficiente para intervenção em caso de acidentes. (SILVA, 2017)

O PAEBM precisa ser incessantemente divulgado junto à população da zona de influência da barragem, nas escolas, universidades, igrejas, sindicatos e órgãos públicos, para que esta população conheça os riscos a que está sujeita. Importante também que o empreendedor da barragem promova junto à população sujeita a riscos, simulações periódicas de atuação em caso de emergência, como evacuação das áreas de inundação pela lama.

A informação dos riscos à população afetada, bem como a criação de mecanismos de participação e controle social, inclusive são alguns dos fundamentos da PNSB:

\footnotetext{
${ }^{4}$ O Dano Potencial Associado assemelhasse aos impactos relativos a uma possível ruptura da barragem ou outro acidente ou incidente que tenha como plano de foco o barramento. A Resolução CNRH no 143/2012 define Dano Potencial Associado como o dano que pode ocorrer devido ao rompimento, vazamento, infiltração no solo ou mau funcionamento de uma barragem, independentemente da sua probabilidade de ocorrência, podendo ser mensurado pelas perdas de vidas humanas e impactos sociais, econômicos e ambientais. (SILVA, 2017, p.101)
} 
Art. 4ำ São fundamentos da Política Nacional de Segurança de Barragens (PNSB):

I - a segurança de uma barragem deve ser considerada nas suas fases de planejamento, projeto, construção, primeiro enchimento e primeiro vertimento, operação, desativação e de usos futuros;

II - a população deve ser informada e estimulada a participar, direta ou indiretamente, das ações preventivas e emergenciais;

III - o empreendedor é o responsável legal pela segurança da barragem, cabendo-lhe o desenvolvimento de ações para garanti-la;

IV - a promoção de mecanismos de participação e controle social;

$\mathrm{V}$ - a segurança de uma barragem influi diretamente na sua sustentabilidade e no alcance de seus potenciais efeitos sociais e ambientais. (BRASIL, 1988, grifo nosso)

Uma forma de informar a população acerca dos prováveis riscos em casos de desastres envolvendo barragens é através da publicização de estudos realizados com base no método Dam Break.

A análise no método Dam Break é baseada em uma ruptura hipotética e consiste de um prognóstico da inundação ou devastação proveniente do extravasamento do material contido em uma ou mais barragens. Essa análise busca demonstrar o pior cenário possível em um suposto acidente com o barramento. Os estudos iniciam-se pela análise de incidentes como dos processos de abertura de brecha associados às várias falhas possíveis que ameaçam a estabilidade estrutural do paramento. Como consequência do incidente, vislumbra-se o caminho a ser percorrido pela onda cheia e o alcance dessa onda, utilizando simulações e computação gráfica. Por fim, os resultados obtidos são geoprocessados e a extensão dos danos potenciais definidos e apresentados em mapas temáticos, como os mapas de Kernel. (SILVA, 2017, p.145)

O real conhecimento dos prováveis danos em caso de desastres com barragens pela população sujeita aos mesmos, é uma exigência que decorre do próprio cenário de risco a que a sociedade está sujeita. Numa sociedade de riscos a criação no imaginário coletivo de um estado de alerta permanente é medida de bom senso e que deve ser estimulada pelo Estado e pelo empreendedor da barragem e promovido através da educação ambiental.

Há que se destacar que o incentivo a criação de um estado de alerta permanente na população decorre principalmente do elevado número de barragens existentes no Brasil. Conforme informações da Agencia Nacional de Águas - ANA, havia no Brasil, 
até o último levantamento referente ao ano de 2015, aproximadamente 263 barragens classificadas como exclusivamente de rejeitos de minério, sendo que 114 se encontram em território mineiro e fiscalizados pelo DNPM. (SILVA, 2017, p.106)

Já o DNPM apresenta outros dados. Segundo este órgão "até o final do ano de 2014, foram totalizadas 399 barragens de rejeito de minério de ferro fiscalizadas pelo órgão que se enquadravam nos termos do artigo 1ํ da Lei Federal no 12.334/2010, ou seja, na Política Nacional de Segurança de Barragens". Dentre estas barragens 18 enquadraram-se no "nível de baixíssima segurança, com altos riscos e danos potenciais, exigindo intervenções imediatas para a solução dos problemas apresentados". (SILVA, 2017, p.101)

Por outro lado, o Inventário Anual de Barragens do ano de 2015 apontou que existem 730 barramentos em Minas Gerais, sendo que 442 delas destinam-se a depósito de rejeitos de minério. (SILVA, 2017, p.111)

Gráfico 1 - Evolução do número de estruturas cadastradas no Banco de Desenvolvimento Ambiental de Minas Gerais. (MINAS GERAIS, 2016, p.22)

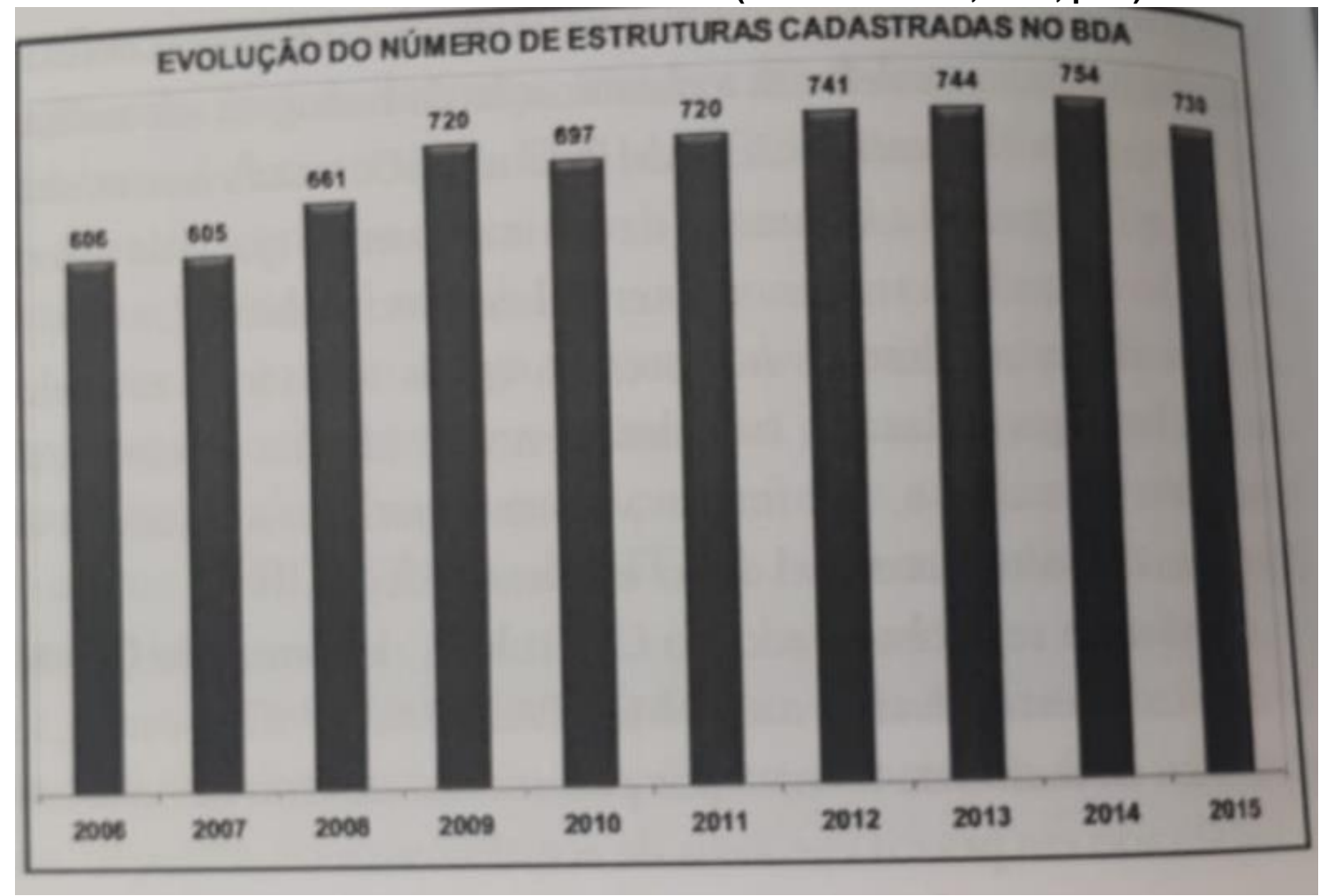

Fonte: (MINAS GERAIS, 2016, p.22) 
Minas Gerais, o próprio nome já diz, é um estado que tem por vocação natural a exploração de atividade minerária e consequentemente é o mais atingido por desastres envolvendo barragens. Apenas nos últimos 18 anos houve 7 desastres envolvendo barragens, os quais foram responsáveis pela morte de mais de 300 pessoas e por deixar mais de 5 mil pessoas desabrigadas ou desalojadas.

Motivado por tal fato, conforme 0 artigo 30 da lei estadual № 21.972/2016 (Dispõe sobre o Sistema Estadual de Meio Ambiente e Recursos Hídricos - Sisema) o Poder Executivo do estado "fomentará, por todos os meios, alternativas à implantação de barragens, com a finalidade de promover a preservação do meio ambiente e a redução dos impactos ambientais gerados por empreendimentos de mineração". (MINAS GERAIS, 2016)

Outro ponto que merece destaque é a fiscalização das barragens. A PNSB determina que a fiscalização da segurança de barragens de rejeitos minerários caberá à entidade outorgante de direitos minerários para fins de disposição final ou temporária de rejeitos, sem prejuízo das ações fiscalizatórias dos órgãos ambientais integrantes do Sistema Nacional do Meio Ambiente (Sisnama).

Uma fiscalização eficiente pelos órgãos públicos acerca do estado de segurança da barragem proporcionará a manutenção de informações atualizadas à população e ao Poder Público e a adoção de medidas preventivas e mitigadoras com antecedência à concretização de um possível evento adverso envolvendo a estrutura.

Novamente cabe destacar a importância de se criar na coletividade um estado de alerta permanente acerca dos riscos oriundos de possíveis desastres com as barragens existentes na proximidade. A própria PNSB em seus artigos 13 e 15 determina instituição do Sistema Nacional de Informações sobre Segurança de Barragens (SNISB) e o estabelecimento de um "programa de educação e de comunicação sobre segurança de barragem, com o objetivo de conscientizar a sociedade da importância da segurança de barragens", respectivamente.

O mencionado programa de educação e de comunicação sobre segurança de barragens contemplará no mínimo as seguintes medidas: I - apoio e promoção de ações descentralizadas para conscientização e desenvolvimento de conhecimento sobre segurança de barragens; II - elaboração de material didático; III - manutenção de 
sistema de divulgação sobre a segurança das barragens sob sua jurisdição; IV promoção de parcerias com instituições de ensino, pesquisa e associações técnicas relacionadas à engenharia de barragens e áreas afins; e V - disponibilização anual do Relatório de Segurança de Barragens.

Acredita-se que diante de um cenário de elevado número de barragens, da reincidência constatada com desastres envolvendo estas estruturas e dos altos riscos de rompimento já constatados em alguns barramentos, bem como dos danos potenciais associados de grande monta, será somente através de uma fiscalização mais eficiente e da ampliação de medidas de conscientização da população acerca do real cenário de riscos a que está exposta que poderá ser modificado o caótico cenário de acidentes envolvendo barragens no Brasil e ampliada a proteção ambiental no país, a fim de garantir a todos os constitucionalmente previstos direitos à vida, à saúde, à moradia, à propriedade e ao meio ambiente ecologicamente equilibrado.

\section{ESTADO DE COISAS INCONSTITUCIONAL}

O Estado de Coisas Inconstitucional é uma tese criada pela Corte Constitucional da Colômbia na qual declara-se a existência de uma violação massiva de direitos fundamentais ocasionadas por falhas sistêmicas de determinada ação do governo.

A Corte Constitucional da Colômbia definiu o Estado de Coisas Inconstitucional como "la declaratória que hace la Corte Constitucional, cuando se constata la vulneración repetida y constante de derechos fundamentales que afectan a multitud de personas, cuya solución requiere la intervención de distintas entidades para atender problemas de orden estructural". (COLÔMBIA, 2004)

Em 1997 a Corte Constitucional da Colômbia - CCC, em decisão de teor inédito inovou sua jurisprudência e declarou o Estado de Coisas Inconstitucional na Sentencia de Unificación no 559. No caso em questão, os professores da rede pública de ensino dos municípios de Marí ala Baja e Zambrano arguiram que não receberam os benefícios previdenciários por não terem sido filiados a um banco ou fundo de previdência social, mesmo tendo contribuído com $5 \%$ de seus salários para tal finalidade. Os Municípios em comento deixaram de filiar seus professores ao Fondo 
Nacional de Prestaciones Sociales del Magisteri e utilizaram os valores oriundos das contribuições destes para custear outras despesas, violando assim o direito à vida, à saúde e à segurança social destes profissionais. (ROSENDA, 2017)

Diante de tal cenário a Corte Constitucional então declarou o Estado de Coisas Inconstitucional e determinou que os municípios corrigissem a inconstitucionalidade em prazo razoável.

Logo em 1998 a CCC na Sentencia T-068 declarou novamente o Estado de Coisas Inconstitucional em face da inércia da Caja Nacional de Previsión Social em responder os pedidos de reconhecimento e revalidação das pensões e verbas previdenciárias. A demora na resposta a tais pedidos acarretou no ajuizamento de mais de 30.000 ações contra a entidade. A Corte Constitucional entendeu que a situação narrada além de afetar direitos individuais, afetava também todo o Poder Judiciário que ficou congestionado com a apreciação de tantas demandas, o que prejudicava 0 exercício de sua função. (ROSENDA, 2017)

Ainda em 1998 a Corte Constitucional da Colômbia reconheceu e declarou o Estado de Coisas Inconstitucional em mais duas oportunidades, na Sentencia de Unificación no 250 e na Sentencia de Tutela T-153. Referidos casos referiram-se respectivamente a inobservância da exigência de realização de concurso público para tabelião e a precariedade do sistema carcerário face a superlotação das penitenciárias. (ROSENDA, 2017)

Em 2004 a CCC novamente declarou o Estado de Coisas Inconstitucional, dessa vez em face do quadro caótico de deslocamento forçado de pessoas em razão da violência urbana e da atuação das Forças Armadas Revolucionárias da Colômbia FARC. Nesta oportunidade a Corte ordenou a formulação de políticas públicas, a elaboração de leis e de um marco regulatório hábil a proteger os direitos envolvidos. (ROSENDA, 2017)

Embora tenha sido declarado reiteradas vezes ao longo dos últimos vinte e dois anos, o Estado de Coisas Inconstitucional possui diversos pressupostos para sua caracterização, os quais devem estar totalmente presentes no caso em tela para viabilizar seu reconhecimento. 
Segundo ensinamentos de Carlos Alexandre de Azevedo Campos são pressupostos essenciais para a caracterização do $\mathrm{ECl}$ : a) a existência de um cenário de violação massiva, reiterada, generalizada e sistemática de direitos fundamentais, que atinja um número elevado de pessoas; b) a ausência de coordenação entre as medidas legislativas, administrativas e orçamentárias que acarrete a inefetividade destas e exija uma mudança estrutural para cessar com as violações de direitos fundamentais constatadas; c) a duradoura inércia das autoridades públicas e; d) a possibilidade de congestionamento do Poder Judiciário em caso de ajuizamento de ação individual por todos aqueles que tiveram seus direitos violados. (CAMPOS, 2015)

No Brasil o $\mathrm{ECl}$ somente foi declarado uma única vez pelo Supremo Tribunal Federal, no bojo da Arguição de Descumprimento de Preceito Fundamental - ADPF no 347 ajuizada pelo Partido Socialismo e Liberdade - PSOL, na qual o partido postulou o reconhecimento do $\mathrm{ECl}$ em face da violação massiva de direitos fundamentais da população carcerária do país ocasionada pelas condições degradantes do sistema prisional, como a superlotação e a precariedade das instalações prisionais

No caso em análise a medida cautelar requerida foi parcialmente deferida, determinando-se aos juízes e tribunais que realizassem audiências de custódia no prazo máximo de 90 dias, com o comparecimento do preso perante a autoridade judiciária no prazo máximo de 24 horas, bem como determinou à União que liberasse "o saldo acumulado do Fundo Penitenciário Nacional para utilização com a finalidade para a qual foi criado, abstendo-se de realizar novos contingenciamentos". (BRASIL, 2015)

Não obstante só tenha sido declarado uma vez, acredita-se que há no Brasil diversos outros casos passíveis de caracterização do Estado de Coisas Inconstitucionais, como ocorre com o cenário de reincidentes rompimentos de barragens no Brasil e de permanente insegurança ocasionada por barragens de rejeitos de minério.

Desse modo, demonstrar-se-á adiante o cumprimento de todos os pressupostos essenciais de caracterização do Estado de Coisas Inconstitucional pelo atual quadro de insegurança e reincidentes desastres pelo rompimento de barragens de rejeitos de minérios no país. 


\subsection{A caracterização do estado de coisas inconstitucional face ao reiterado rompimento de barragens e a manutenção dos elevados danos decorrentes de impactos de fenômenos naturais no Brasil}

$O$ atual quadro de insegurança e violação de direitos fundamentais ocasionado pelo reiterado rompimento de barragens no Brasil ao longo dos últimos 12 anos (8 desastres envolvendo a ruptura de barramentos) cumpre todos os requisitos para caracterização do Estado de Coisas Inconstitucional. É o que demonstrar-se-á detalhadamente adiante.

O primeiro dos pressupostos essenciais do $\mathrm{ECl}$ é a existência de um cenário de violação massiva, reiterada, generalizada e sistemática de direitos fundamentais, que atinja um número elevado de pessoas. $O$ atual quadro de rompimento reiterado de barragens cumpre perfeitamente tal requisito, afinal nos últimos 12 anos ocorreram 8 desastres com o rompimento de barragens no país, os quais acarretaram mais de 150 óbitos, o desaparecimento de mais de 300 pessoas, e deixaram aproximadamente sete mil desabrigados ou desalojados, afetando, portanto, o direito fundamental à vida, à moradia, à saúde, à propriedade e ao meio ambiente ecologicamente equilibrado de milhares de pessoas.

O segundo pressuposto essencial é a ausência de coordenação entre as medidas legislativas, administrativas e orçamentárias que acarrete a inefetividade destas e exija uma mudança estrutural para cessar com as violações de direitos fundamentais constatadas. O cumprimento de tal requisito denota da própria reincidência do rompimento de barragens mesmo após a edição de vasta legislação relativa à segurança de barragens e a gestão de riscos de desastres, como a Lei no 12.334/2010 (Política Nacional de Segurança de Barragens) e a Lei 12.608/2012 (Política Nacional de Proteção e Defesa Civil). Veja-se que depois de 2010 já houve 5 desastres ocasionados por rompimento de barragens no país e muitas barragens permanecem enquadradas na classificação de alto risco.

As medidas legais e administrativas, portanto, se mostraram ineficazes para mudar o cenário de insegurança e lesão a direitos fundamentais ocasionados pelo rompimento de barramentos, sendo necessária a adoção de complexas medidas 
estruturais para alterar esse ambiente e promover uma maior segurança a população neste aspecto.

O terceiro pressuposto essencial para concretização do ECl é a duradoura inércia das autoridades públicas para resolver o problema. Tal fato pode ser observado pela manutenção do quadro de pouca fiscalização existente e pela reincidência dos eventos adversos e da lesão a direitos fundamentais da população atingida.

Por fim o derradeiro requisito para a existência do $\mathrm{ECl}$ é a possibilidade de congestionamento do Poder Judiciário em caso de ajuizamento de ação individual por todos aqueles que tiveram seus direitos violados. Esse requisito é o mais fácil de ser demonstrado afinal, consoante o princípio de inafastabilidade da jurisdição, se todos aqueles que sofreram prejuízos materiais com os danos decorrentes do rompimento das barragens (dano ambiental reflexo) ajuizarem ações de indenização em face da empreendedora da barragem, serão dezenas de milhares de ações em tramitação, o que prejudicará obviamente o regular funcionamento do Poder Judiciário, principalmente se considerarmos a modesta estrutura das comarcas de Brumadinho/MG e Mariana/MG.

Face ao exposto concebe-se que a permanente e elevada violação a direitos fundamentais decorrentes do rompimento reiterado de barragens no Brasil nos últimos anos caracteriza-se em Estado de Coisas Inconstitucional, sendo cabível sua declaração pelo STF, caso provocado para tanto.

Cabe ressaltar que há contundentes críticas à declaração do Estado de Coisas Inconstitucionais na doutrina brasileira, as quais merecem destaque em momento oportuno. Não obstante acredita-se que tal momento não é no bojo deste estudo, de modo que objetiva-se com a presente pesquisa identificar a possibilidade de enquadramento do atual cenário de reincidentes rompimentos de barragens como Estado de Coisas Inconstitucional e não a pertinência jurídica deste instituto.

\subsection{Proposições para sanar o estado de coisas inconstitucional decorrente da massiva lesão de direitos fundamentais ocasionadas pelo reiterado rompimento de barragens no Brasil}


A mera declaração do Estado de Coisas Inconstitucional não é capaz, por si só, de afastar o cenário de massiva e contínua lesão a direitos fundamentais da população, seja em qual caso este seja declarado.

Dessa forma, a adoção de medidas concretas deve ser determinada pelo Poder Judiciário, como a elaboração de políticas públicas pelo Poder Executivo e a edição de leis pelo Poder Legislativo.

Sendo assim, no intuito de contribuir para a superação do atual deplorável cenário de rompimentos constantes de barragens no país, aponta-se como sugestões:

a) A criação de um Comitê Tripartite de Fiscalização de Barragens, composto por membros da União, dos Estados, dos Municípios e do Distrito Federal destinado a fiscalizar todas as barragens existentes no país no prazo de 6 meses.

b) A alteração do Estatuto das Cidades (Lei 10.257/2001) para incluir como exigência dos Planos Diretores de cidades que contenham barragens de rejeitos minerários a instalação de equipamentos visuais nas zonas de autossalvamento, bem como a previsão destas na lei de uso e ocupação do solo;

c) A determinação da implantação de sinalização nas vias das localidades provavelmente atingidas em caso de ruptura de barragens (as quais são identificadas por analises com o método Dam Break), informando serem aquelas áreas sujeitas a impactos negativos em casos de desastres, bem como a implantação de estruturas de instrumentalização dos sistemas de alerta precoce e de sinalização capaz de orientar a evacuação da área.

d) A determinação de realização de cursos anuais nas escolas de ensino regular, nas universidades e nos órgãos públicos, custeados pelo empreendedor da barragem, para apresentação dos dados relativos às barragens situadas no município, como os relacionados ao licenciamento, as informações obtidas com as últimas fiscalizações, o Plano de Ação Emergencial, ao dano potencial associado e para proporcionar a população do município o conhecimento de quais são as áreas da cidade provavelmente afetadas em caso de ruptura, com base em analises realizadas com utilização do método Dam Break. 
e) A realização semestral nas escolas de ensino regular e nos órgãos públicos de exercícios de simulação de reação em casos de desastre envolvendo o rompimento das barragens existentes no município, promovidos e custeados pelo empreendedor das barragens.

Percebe-se que as medidas sugeridas nos itens "c", "d" e "e" destinam-se a promover no imaginário coletivo da população situada em municípios que contenham barragens um "permanente estado de alerta".

Referida medida não visa aterrorizar a população, mas sim prepará-la para o pior cenário e conscientizá-la dos riscos a que está sujeita. Se a sociedade é de risco o estado de alerta permanente é medida que se impõe.

\section{CONCLUSÃO}

Realizou-se no presente estudo uma análise dos desastres oriundos do rompimento de barragens ocorridos principalmente no Brasil ao longo dos últimos anos, bem como da atual legislação responsável por promover a segurança das barragens, no intuito de identificar as falhas estruturais responsáveis por permitir a perenização da reincidência de eventos dessa natureza e consequentemente a concretização de elevados danos à população atingida, os quais afetam diretamente diversos de seus direitos fundamentais, como o direito à vida, à saúde, à moradia, à propriedade e ao meio ambiente ecologicamente equilibrado.

Alcançou-se com relativo êxito os objetivos específicos propostos. A identificação das barragens em que houve rompimento nas últimas duas décadas foi realizada na tabela 2 - Rompimentos de Barragem no Brasil.

A apresentação da legislação existente referente à segurança de barragens no Brasil foi realizada na seção 2.1. A conceituação do Estado de Coisas Inconstitucional e a apresentação dos requisitos essenciais para sua caracterização ocorreu na seção 3.

Já no que tange a identificação dos dados quantitativos dos danos decorrentes dos rompimentos de barragens de Mariana e Brumadinho, não foi possível alcançá-la com precisão porque os danos do desastre ocorrido em Brumadinho ainda estão sendo 
contabilizados pelos órgãos competentes, não havendo informações oficiais definitivas acerca destes.

Diante de todas as informações obtidas, conclui-se ser possível a caracterização do Estado de Coisas Inconstitucional face ao quadro de constante e elevada violação a direitos fundamentais decorrentes do rompimento reiterado de barragens no Brasil nos últimos anos.

A fim de superar o cenário de massiva violação de direitos fundamentais constatado, apontou-se como sugestão a adoção das seguintes medidas: a) A criação de um Comitê Tripartite de Fiscalização de Barragens, composto por membros da União, dos Estados, dos Municípios e do Distrito Federal destinado a fiscalizar todas as barragens existentes no país no prazo de 6 meses; b) A alteração do Estatuto das Cidades (Lei 10.257/2001) para incluir como exigência dos Planos Diretores de cidades que contenham barragens de rejeitos minerários a instalação de equipamentos visuais nas zonas de autossalvamento, bem como a previsão destas na lei de uso e ocupação do solo; c) A determinação da implantação de sinalização nas vias das localidades provavelmente atingidas em caso de ruptura de barragens (as quais são identificadas por analises com o método Dam Break), informando serem aqueles áreas sujeitas a impactos negativos em casos de desastres, bem como a implantação de estruturas de instrumentalização dos sistemas de alerta precoce e de sinalização capaz de orientar a evacuação da área; d) A determinação de realização de cursos anuais nas escolas de ensino regular, nas universidades e nos órgãos públicos, custeados pelo empreendedor da barragem, para apresentação dos dados relativos as barragens situadas no município, como os relacionados ao licenciamento, as informações obtidas com as últimas fiscalizações, o Plano de Ação Emergencial, ao dano potencial associado e para proporcionar a população do município o conhecimento de quais são as áreas da cidades provavelmente afetadas em caso de ruptura, com base em análises realizadas com utilização do método Dam Break; e e) A realização semestral nas escolas de ensino regular e nos órgãos públicos de exercícios de simulação de reação em casos de desastre envolvendo o rompimento das barragens existentes no município, promovidos e custeados pelo empreendedor das barragens. 
Despertar no imaginário coletivo das populações dos municípios que contenham barragens um "permanente estado de alerta" é o principal objetivo a ser alcançado com as medidas sugeridas, não para aterrorizar a população, mas sim para prepará-la para reagir no pior cenário e conscientizá-la dos riscos a que está sujeita. Se a sociedade é de risco o estado de alerta permanente é medida que se impõe.

\section{REFERÊNCIAS}

ALVES, Henrique Rosmaninho. O rompimento de barragens no brasil e no mundo: desastres mistos ou tecnológicos? Disponível em: < http://www.domhelder.edu.br/uploads/artigo_HRA.pdf >. Acesso em 31 de janeiro de 2019.

ASSOCIAÇÃO BRASILEIRA DE NORMAS TÉCNICAS - ABNT. NBR 13.028:

Mineração - Elaboração e apresentação de projeto de barragens para disposição de rejeitos, contenção de sedimentos e reservação de água - Requisitos. Rio de Janeiro, ABNT, 2017.

BRASIL. Supremo Tribunal Federal. ADPF no 347 MC/DF, Rel. Min. Marco Aurélio. 2015.

Lei no 9.433, de 08 de janeiro de 1997. Institui a Política Nacional de Recursos Hídricos, cria o Sistema Nacional de Gerenciamento de Recursos Hídricos, regulamenta o inciso XIX do art. 21 da Constituição Federal, e altera 0 art. $1^{\circ}$ da Lei no 8.001, de 13 de março de 1990, que modificou a Lei № 7.990, de 28 de dezembro de 1989. Diário Oficial, 09 de janeiro de 1997.

. Lei no 12.334, de 20 de setembro de 2010. Estabelece a Política Nacional de Segurança de Barragens destinadas à acumulação de água para quaisquer usos, à disposição final ou temporária de rejeitos e à acumulação de resíduos industriais, cria o Sistema Nacional de Informações sobre Segurança de Barragens e altera a redação do art. 35 da Lei $n^{\circ} 9.433$, de 8 de janeiro de 1997, e do art. $4^{\circ}$ da Lei $n^{\circ} 9.984$, de 17 de julho de 2000. Diário Oficial, 21 de setembro de 2010.

. Constituição da República Federativa do Brasil de 1988. Brasília: Diário Oficial, 5 de Outubro de 1988

BROWN, David. et al. 501 Desastres mais devastadores de todos os tempos. Trad. Catharina Pinheiro. 1ํㅡㄹ edição brasileira. São Paulo: Editora Lafonte, 2012.

CAMPOS, Carlos Alexandre de Azevedo. O Estado de Coisas Inconstitucional e o litígio estrutural. In: Revista Consultor Jurídico. Disponível em: <http://www.conjur.com.br/2015-set01/carlos-campos-estado-coisas-inconstitucionallitigio-estrutural>. Acesso em 29 de janeiro de 2019. 
COLÔMBIA. Corte Constitucional da Colômbia. Sentencia ST - 025, de 22/01/2004. Disponível em: < http://www.corteconstitucional.gov.co/relatoria/2004/T-025-04.htm >. Acesso em 29 de janeiro de 2019.

DEPARTAMENTO DE ÁGUAS E ENERGIA ELÉTRICA DO ESTADO DE SÃO PAULO - DAEE/SP. Portaria no 717, de 12 de Dezembro de 1996. Disponível em: < http://www.daee.sp.gov.br/legislacao/arquivos/850/portaria\%20daee_717.pdf >. Acesso em 29 de janeiro de 2019.

ROSENDA, Kamila Rodrigues. A declaração de estado de coisas inconstitucional na ADPF 347 e o princípio da separação de poderes. In: FERREIRA, Pedro Paulo da Cunha; CARVALHO, Thiago Ribeiro de. Questões atuais do direito brasileiro e a jurisprudência do STF. Rio de Janeiro: Lumen Juris, 2017.

SILVA, Alexander Marques. Sociedade de risco e as barragens de rejeitos. Rio de Janeiro: Lumen Juris, 2017. 